\title{
The risk of foot ulceration in diabetic patients with high foot pressure: a prospective study
}

\author{
A. Veves, H.J.Murray, M.J. Young and A. J. M. Boulton \\ Diabetes Centre, Manchester Royal Infirmary, Manchester, UK
}

\begin{abstract}
Summary. Foot ulceration results in substantial morbidity amongst diabetic patients. We have studied prospectively the relationship between high foot pressures and foot ulceration using an optical pedobarograph. A series of 86 diabetic patients, mean age 53.3 (range 17-77) years, mean duration of diabetes 17.1 (range 1-36) years, were followed-up for a mean period of 30 (range 15-34) months. Clinical neuropathy was present in $58(67 \%)$ patients at baseline examination. Mean peak foot pressure was higher at the follow-up compared to baseline $\left(13.5 \mathrm{~kg} \cdot \mathrm{cm}^{-2} \pm 7.1 \mathrm{SD}\right.$ vs $11.2 \pm 5.4$, $p<0.001)$ with abnormally high foot pressures $(>12.3)$ being present in 55 patients at follow-up and 43 at the baseline visit $(p=\mathrm{NS})$. Plantar foot ulcers developed in 21 feet
\end{abstract}

of 15 patients ( $17 \%$ ), all of whom had abnormally high pressures at baseline; neuropathy was present in 14 patients at baseline. Non-plantar ulcers occurred in $8(9 \%)$ patients. Thus, plantar ulceration occurred in $35 \%$ of diabetic patients with high foot pressures but in none of those with normal pressures. We have shown for the first time in a prospective study that high plantar foot pressures in diabetic patients are strongly predictive of subsequent plantar ulceration, especially in the presence of neuropathy.

Key words: Diabetes mellitus, neuropathy, foot ulceration, risk factors, foot pressures.
Foot problems are important contributory factors to the high morbidity and mortality observed in diabetic patients while the economic impact is also substantial [1]. Early identification of the at-risk patient may be important in preventing foot problems as it has been shown that patient education and a multi-disciplinary approach can reduce the rate of amputation in susceptible diabetic patients $[2,3]$.

Neuropathy and limited joint mobility have been found to be the two main aetiological factors of the high foot pressures that are often found in diabetic patients and are associated with foot ulceration [4-6]. Previous studies $[4,7,8]$ have shown that foot ulcers are found at sites with high pressures but that in the absence of neuropathy high pressures alone do not lead to ulceration. However, as Cavanagh and Ulbrecht [9] pointed out, all these studies are cross-sectional and no prospective study has been undertaken to examine the incidence of foot ulceration in diabetic patients with high foot pressures.

In the present study we therefore elected to study prospectively foot pressure changes and their association with foot ulceration in a high risk group of diabetic patients. The main aim was to assess whether foot pressure measurements could be used to predict the patient at risk of foot ulceration.

\section{Patients and methods}

Diabetic patients attending clinics at the Manchester Diabetes Centre were randomly invited to take part in the study. Patients with previous amputation, active foot ulcers or who were unable to walk normally without aid for any reason were excluded from the study. The patients who agreed to take part were divided into two groups: a neuropathic group which included all subjects with neuropathy on clinical examination, and a non-neuropathic group. A modified neuropathy deficit score (NDS) was used to diagnose neuropathy and was based on reduced or absent ankle reflexes and reduced or absent sensation to pain, touch and vibration [10]. Reflexes were scored as 0 if they were present, 1 if elicited with reinforcement and 2 if absent. Pain, touch and vibration perception were scored as 0 if normal, 1 if reduced, 2 if absent, and the average score of both feet was calculated. Neuropathy was diagnosed if the total score of reflexes from both feet and the average sensory examination score was 5 or more.

One hundred and fifty-one patients were seen at baseline and had their foot pressures measured. All patients received the same education about foot care and were provided with the appropriate footwear as needed. Those who developed foot ulcers were followed up at the Diabetic Foot Clinic whose structure and function has been described elsewhere [3]. The site of any ulcers that developed during the study was recorded and ulcers were classified as plantar when they occurred on the plantar surface of the foot and as dorsal if they occurred anywhere else on the foot. After a mean period of 30 (range 
Table 1. Patient details

\begin{tabular}{llll}
\hline & $\begin{array}{l}\text { Diabetic } \\
\text { group }\end{array}$ & $\begin{array}{l}\text { Neuro- } \\
\text { pathic } \\
\text { sub-group }\end{array}$ & $\begin{array}{l}\text { Non-neuro- } \\
\text { pathic } \\
\text { sub-group }\end{array}$ \\
\hline $\begin{array}{l}\text { No. of subjects } \\
\begin{array}{l}\text { Age (years) } \\
\text { (range) }\end{array}\end{array}$ & 86 & 58 & 28 \\
Weight & 53.4 & $56.3^{\mathrm{a}}$ & $47.9^{\mathrm{a}}$ \\
(kg, SD) & $(17-77)$ & $(28-77)$ & $(17-66)$ \\
Male/Female & $74.4 \pm 16.5$ & $74.8 \pm 17.2$ & $74.4 \pm 15.0$ \\
$\begin{array}{l}\text { Type 1 diabetes/ } \\
\text { Type 2 diabetes }\end{array}$ & $61 / 25$ & $41 / 17$ & $20 / 8$ \\
$\begin{array}{l}\text { Diabetes duration (years) } \\
\text { (range) }\end{array}$ & $36 / 50$ & $25 / 33$ & $11 / 17$ \\
\hline
\end{tabular}

${ }^{\mathrm{a}} p<0.001$

15-34) months from the first visit all patients were invited to return for foot pressure measurements.

Fourteen non-diabetic subjects (mean age 38 years, range 23-57) served as control subjects in order to ensure that foot pressures do not change significantly with time in healthy individuals. Their foot pressures were measured at baseline and for a second time after a mean period of 35 (range 14-42) months. All control subjects were able to walk normally and none had a history of foot problems.

Foot pressures were measured by optical pedobarography as described elsewhere [11]. All patients had regular chiropody during the study so excessive callus formation, which could influence the pressure recordings, did not develop. Three footsteps from each foot were recorded during bare foot gait. The footstep most representative of their usual gait, as judged by the same experienced operator, was used for analysis and pressure was measured under the metatarsal heads, heel, the great toe and any other area with high pressure. The peak pressure of each foot was used for analysis irrespective of the area under which it occurred. Peak pressures more than $12.3 \mathrm{~kg} \cdot \mathrm{cm}^{-2}$ were considered to be abnormal according to a previous study which included a large number of healthy subjects [12].

The vibration perception threshold (VPT) was measured at the great toe by biothesiometry (Arnold Horwell, London, UK) during the follow-up visit in all patients and healthy subjects as described elsewhere [13]. The upper threshold of normality was taken from published data based on measurements of a large number of healthy subjects [13]. The study was approved by the Central Manchester Health Authority ethical committee.

\section{Statistical analysis}

Statistical analysis was conducted using the Minitab statistical software (Minitab, Inc., State College, Pa., USA). The Wilcoxon's matched pairs signed rank test was employed for the comparisons between the baseline and follow-up in the different groups and the Mann-Whitney and chi-square tests for the comparison between the groups.

\section{Results}

From the 151 patients studied at baseline 11 were known to have died, one to have had a traumatic amputation and four to have left the area at the time of the second visit. From the remaining 135 patients, $86(64 \%)$ responded and were seen for the follow-up visit: only those seen at both visits were included in the analysis. No difference at baseline existed between the patients who were seen and those who did not attend the second visit. Fifty-eight $(67 \%)$ patients had neuropathy at baseline forming the neuropathic subgroup while $28(33 \%)$ without neuro- pathy formed the non-neuropathic group (Table 1). The mean peak pressure in the diabetic patients at the followup visit was significantly higher compared to the first visit $\left(13.5 \mathrm{~kg} \cdot \mathrm{cm}^{-2} \pm 7.1 \mathrm{SD}\right.$ vs $\left.11.2 \pm 5.4, p<0.001\right)$ but the number of patients with abnormally high foot pressures $(>12.3)$ in either foot was similar during both follow-up and baseline visits (55 vs 43 patients, $p=$ NS, Table 2 ). The mean peak pressure increased in both the neuropathic group $\left(14.8 \pm 7.3\right.$ vs $12.2 \pm 5.8 \mathrm{~kg} \cdot \mathrm{cm}^{-2}, p<$ $0.001)$ and the non-neuropathic group $(10.9 \pm 5.6$ vs $9.0 \pm 3.9 \mathrm{~kg} \cdot \mathrm{cm}^{-2}, p<0.005$, Table 2). Similar numbers of patients had high pressures at follow-up and baseline visits in both the neuropathic (42 vs 31 patients, $p=\mathrm{NS}$ ) and the non-neuropathic (13 vs 12 patients, $p=$ NS) subgroups. In contrast, no significant difference was found in the mean peak pressure of the control group $(7.7 \pm 3.0 \mathrm{vs}$ $7.9 \pm 3.6 \mathrm{~kg} \cdot \mathrm{cm}^{-2}, p=\mathrm{NS}$ ) and the number of subjects with abnormally high pressures at both visits (4 vs 3, $p=\mathrm{NS}$ ).

Plantar ulcers developed in $15(17 \%)$ patients or in 21 $(12 \%)$ feet during the study, and dorsal ulcers in $8(9 \%)$ patients. Seven ( $47 \%$ ) patients who developed plantar ulceration gave a history of previous ulceration. High foot pressures at baseline were present in all 15 patients who developed plantar ulceration during the study. Eight $(38 \%)$ plantar ulcers developed under the area where the peak pressure was found at the first visit. The site of peak pressure was the same at both visits in $71(41 \%)$ feet and different in the remaining $101(59 \%)$ feet.

Neuropathy had been noted in 14 (93\%) patients who developed plantar ulcers at baseline while all 15 had abnormal VPT at the follow-up visit. Neuropathy was also present in 7 patients who developed non-plantar ulcers at baseline and in all patients at the follow-up visit. Therefore, 15 out of $43(35 \%)$ patients with high pressures at baseline developed plantar ulcers during the study. When the diabetic group was subdivided to neuropathic and non-neuropathic subgroups, 14 out of $31(45 \%)$ neuropathic patients and 1 out of $12(8 \%)$ non-neuropathic patients with abnormally high pressures at baseline developed plantar ulcers. In contrast, none of the patients with normal pressures at baseline developed ulcers during the study.

Table 2. Results of foot pressure measurements and plantar ulceration

\begin{tabular}{lcll}
\hline & $\begin{array}{l}\text { Diabetic } \\
\text { patients } \\
(n=86)\end{array}$ & $\begin{array}{l}\text { Neuropathic Non-neuro- } \\
\text { sub group } \\
(n=58)\end{array}$ & $\begin{array}{l}\text { pathic } \\
\text { sub-group } \\
(n=28)\end{array}$ \\
\hline $\begin{array}{l}\text { Baseline peak foot } \\
\text { pressure (mean } \pm \mathrm{SD}, \\
\left.\mathrm{kg} \cdot \mathrm{cm}^{-2}\right)\end{array}$ & $11.2 \pm 5.4^{\mathrm{a}}$ & $12.2 \pm 5.8^{\mathrm{b}}$ & $9.0 \pm 3.9^{\mathrm{c}}$ \\
$\begin{array}{l}\text { Follow-up peak } \\
\text { foot pressure }\end{array}$ & $13.5 \pm 7.1^{\mathrm{a}}$ & $14.8 \pm 7.3^{\mathrm{b}}$ & $10.9 \pm 5.6^{\mathrm{c}}$ \\
$\begin{array}{l}\text { No. of patients with high } \\
\text { foot pressures at baseline }\end{array}$ & $43(50 \%)$ & $31(53 \%)$ & $12(43 \%)$ \\
$\begin{array}{l}\text { No. of patients with } \\
\text { plantar ulceration and } \\
\text { high pressures at baseline }\end{array}$ & $15(35 \%)$ & $14(45 \%)$ & $1(8 \%)$ \\
\hline a, $\mathrm{b} p<0.001{ }^{\mathrm{c}} p<0.005$ & & &
\end{tabular}




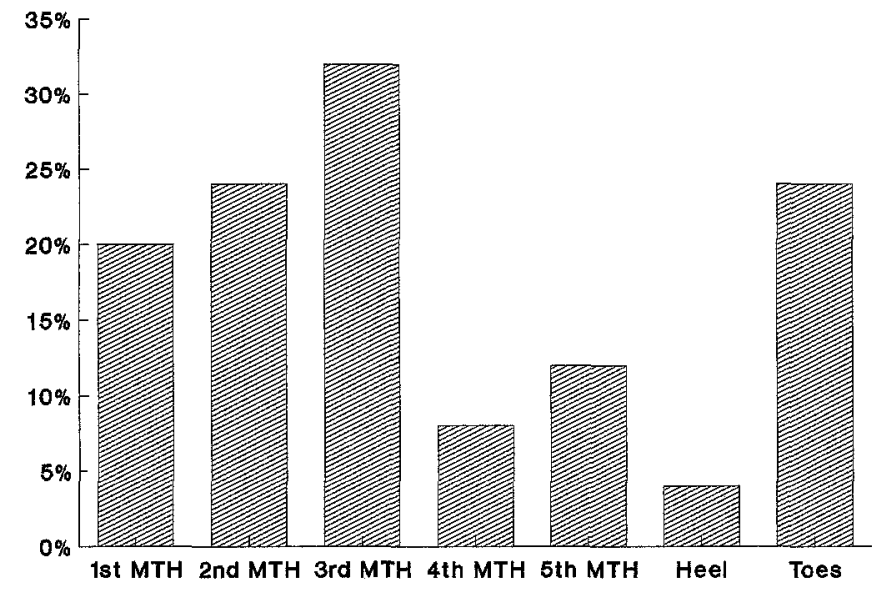

Fig. 1. Distribution of plantar ulcers under the different areas of the foot. MTH: Metatarsal head

The distribution of the ulcers under the different areas of the foot is shown in Figure 1. The area with the highest frequency of ulceration was that under the third metatarsal head ( $32 \%$ ) followed closely by the second metatarsal head and the toes.

Of the 49 patients who failed to attend the follow-up visit for foot pressure reassessment, 5 developed plantar ulcers during the same period of the time, a figure that is not significantly different from the ulceration rate in those patients who completed the study.

\section{Discussion}

Although it has been known for over 30 years that skin ulceration will occur if the epithelium is subjected to external pressure for a period of time [14], the technology of foot pressure measurement systems is still in its relative infancy [15]. The development of techniques such as optical pedobarography $[9,16]$ has enabled investigators to study in detail the previously held belief that high foot pressures were frequently associated with plantar ulceration in the diabetic foot. The first studies using foot pressure measurement systems in diabetic patients were all cross-sectional $[4,7,17]$ but nevertheless all showed a strong association between abnormal vertical loads under the foot and a history of neuropathic ulceration. A subsequent cross-sectional study [8] confirmed that it is the combination of insensitivity secondary to diabetic neuropathy and high foot pressures that results in ulceration, because patients with rheumatoid disease involving the foot had no history of ulceration. In this latter condition, foot pressures as high as those seen in diabetic patients develop, but patients have sufficient protective sensation to safeguard the feet from repetitive trauma that continues in the unprotected diabetic neuropathic foot [8]. Thus, it is the combination of high foot pressures and insensitivity that leads to ulceration in the diabetic neuropathic foot [5].

In the present study, which represents the first prospective study in this area, the risk of foot ulceration was assessed in patients whose foot pressures were measured at baseline and after a mean period of follow-up of
A. Veves et al.: High foot pressures and ulceration: a prospective study

30 months. We have now confirmed that elevated plantar pressures are strongly predictive of subsequent ulceration especially in the presence of neuropathy. The results of the only previous longitudinal study of plantar pressures [18] which showed that the specific high pressure areas under the foot change with time were also confirmed. In contrast to the high-risk group of patients with both high foot pressures and neuropathy, no patient with normal foot pressures developed a plantar ulcer during the present study. It therefore appears that foot pressure measurements can successfully predict, both positively and negatively, foot ulceration in neuropathic patients. Thus, the optical pedobarograph has enabled us to test and confirm the previously held hypothesis of the strong relationship of high foot pressures and neuropathic foot ulceration. However, as discussed in a recent review [16], although useful in research, such sophisticated and expensive foot pressure measurement systems are not essential in routine clinical practice. Simple, semi-quantitative systems such as the Harris-Beath mat [16] can be used to identify high pressure areas, and a careful clinical examination of the foot will detect most high risk areas. Whatever methodo$\operatorname{logy}$ is used to identify these areas, it must be remembered that regular follow-up and examination is essential as such pressure points vary with time.

Previous longitudinal studies have shown that the optical pedobarograph is a reliable method of measuring foot pressures with coefficients of variation for repeated testing being less than $10 \%[18,19]$. In this study we used young healthy subjects, in whom no change in foot pressure would be expected, to establish that the calibration of the system remained stable during the study. Therefore, changes in the diabetic group could not be caused by alterations in the calibration of the optical pedobarograph. Foot pressures are not influenced by the age and weight of patients [12], and a history of previous plantar ulceration is not known to influence pressure recording due to associated structural changes.

The question of the aetiology of high plantar pressures in the neuropathic diabetic foot has recently been addressed $[5,6]$, and it appears that the main contributory factors are sensory and motor dysfunction together with limited joint mobility in the foot. The lack of proprioception with an imbalance between the long flexors and extensors of the toes is thought to lead to the characteristic at-risk foot with claw toes and prominent metatarsal heads. It is therefore not surprising that previous studies have identified measurement of VPT, a measure of large fibre function, as being strongly associated with risk of foot ulceration $[4,20]$. Foot function is then further compromised by the limited joint mobility especially at the sub-talar and metatarsal-phalangeal joints, leading to abnormally high pressures and loads $[6,16]$. Having confirmed the importance of high pressures, early identification and subsequent intervention to protect and cushion the feet is therefore of paramount importance. Appropriate footwear [21, 22] whether extra-depth or custom molded, is indicated for most patients with very high foot pressures. Previous studies have confirmed that padded insoles can reduce and redistribute high pressures [23]. Furthermore, padded hosiery can offer protection to the 
high-risk foot that can be maintained after several months of regular usage [19, 24]. A further therapeutic manoeuvre that can help to reduce foot pressure is the regular trimming of callus tissue [25], which forms in response to repetitive stresses, and can itself act as a foreign body, raise foot pressure and cause ulceration [25].

Education of the patient, proper footwear and an early multi-disciplinary approach to foot problems in a diabetic foot clinic are currently used and have been shown to reduce the rate of amputation $[2,26]$. It can be argued that in this study, despite the education the patients received, the percentage of foot ulceration remained disturbingly high. However, the ulceration rate in those patients who did not attend for the second visit was not significantly different, and there are no other similar prospective studies for comparison. Nevertheless, it must be pointed out that this clinic is a specialist referral centre for diabetic complications and that, therefore, such a highincidence of foot ulceration may not be typical of general diabetes clinics. It should also be remembered that this was not designed as an epidemiological study but its main aim was to investigate risk factors for foot ulceration in high-risk diabetic patients.

A predominance of male subjects (71\%) was noticed when the recruitment of patients had finished. Although surprising at first glance this is in accordance with the male predominance in the general diabetes clinic and the diabetic foot clinic ( $66 \%$ ) of our hospital [3]. Moreover, a recent large epidemiological study has confirmed that foot ulceration is much more common in male patients throughout the UK [27].

In summary, we have shown that high plantar foot pressures in diabetic patients are strongly predictive of subsequent plantar ulceration, especially in the presence of neuropathy, and that they change over a short period of time. Therefore, techniques which can reduce high foot pressures may prevent ulceration in diabetic patients at risk of ulceration.

Acknowledgements. We would like to thank Prof. S. Tomlinson for his continued support and encouragement.

\section{References}

1. Levy LA (1991) Epidemiology and prevention of diabetic foot disease. In: Frykberg RG (ed) The high risk foot in diabetes mellitus. Churchill Livingstone, New York, pp23-30

2. Assal JP, Muhlhauser I, Permat A, Gfeller R, Jorgens V, Berger $M$ (1985) Patient education as the basis for diabetes care in clinical practice and research. Diabetologia 28: 602-613

3. Thomson FJ, Veves A, Ashe H et al. (1991) A team approach to diabetic foot care - the Manchester experience. The Foot 1:7582

4. Boulton AJM, Hardisty CA, Betts RP et al. (1983) Dynamic foot pressures and other studies as diagnostic and management aids in diabetic neuropathy. Diab Care 6: 26-33

5. Boulton AJM (1990) The diabetic foot: neuropathic in aetiology? Diab Med 7: 852-858

6. Fernando DJS, Masson EA, Veves A, Boulton AJM (1991) Relationship of limited joint mobility to abnormal foot pressures and diabetic foot ulceration. Diab Care 14:8-11

7. Ctercteko GC, Dhanendran M, Hutton WC, LeQuesne LP (1981) Vertical forces acting on the feet of diabetic patients with neuropathic ulceration. Br J Surg 68: 608-614
8. Masson EA, Hay EM, Stockley I, Veves A, Betts RP, Boulton AJM (1989) Abnormal foot pressures alone may not cause ulceration. Diab Med 6: 426-428

9. Cavanagh PR, Ulbrecht JS (1991) Plantar pressure in the diabetic foot. In: Sammarco GJ (ed) The foot in diabetes. Lea \& Febiger, Philadelphia, pp 54-70

10. Dyck PJ (1988) Detection, characterization, and staging of polyneuropathy: assessed in diabetics. Muscle Nerve 11: 21-32

11. Masson EA, Boulton AJM (1991) Pressure assessment methods in the foot. In: Frykberg RG (ed) The high risk foot in diabetes mellitus. Churchill Livingstone, New York, pp 139-149

12. Veves A, Fernando DJS, Walewski P, Boulton AJM (1991) A study of plantar pressures in a diabetic clinic population. The Foot 1: 89-91

13. Bloom S, Till S, Sonksen P, Smith S (1984) Use of a biothesiometer to measure individual vibration thresholds and their variation in 519 non-diabetic subjects. Br Med J 288: 233-235

14. Kosiak M (1959) Etiology and pathology of ischemic ulceration. Arch Phys Med Rehab 40: 62-69

15. Lord M (1981) Foot pressure measurement: a review of methodology. J Biomed Engl 3: 91-99

16. Boulton AJM (1991) The importance of abnormal foot pressure and gait in the causation of foot ulceration. In: Bakker K, Kruseman ACN (eds) The Diabetic Foot. Excerpta Medica, Amsterdam, pp 35-50

17. Stokes IAF, Faris IB, Hutton WC (1975) The neuropathic ulcer and loads on the foot in diabetic patients. Acta Orthop Scand 46: 839-847

18. Boulton AJM, Betts RP, Franks CI, Ward JD, Duckworth T (1987) The natural history of foot pressure abnormalities in neuropathic diabetic subjects. Diab Res 5: 73-77

19. Veves A, Masson EA, Fernando DJS, Boulton AJM (1990) Studies of experimental hosiery in diabetic neuropathic patients with high foot pressures. Diab Med 7: 324-326

20. Boulton AJM, Kubrusly DB, Bowker JH et al. (1986) Impaired vibratory perception and diabetic foot ulceration. Diab Med 3: 335-337

21. Coleman WC (1985) The relief of forefoot pressures using outer shoe sole modifications. In: Proceedings of the international congress on biomechanics and kinesiology of the hand and foot. Madras, India, pp 18-31

22. Tovey FE, Moss MJ (1987) Specialist shoes for the diabetic foot. In: Connor H, Boulton AJM, Ward JD (eds) The foot in diabetes. Wiley, Chichester, pp 97-108

23. Schaff P, Kirsch D, Hauser W, Mehnert H (1986) Eine gerateentwicklung zur messung der druckverteilung unter der fußsohle im schuh under deren undvendbarkeit in der diabetologie. Akt Endokr Stoffw 7: 129-136

24. Veves A, Masson EA, Fernando DJS, Boulton AJM (1989) Use of experimental padded hosiery to reduce abnormal foot pressures in diabetic neuropathy. Diab Care 12: 653-655

25. Young MJ, Cavanagh PR, Thomas G, Johnson MM, Murray H, Boulton AJM (1992) The effect of callus removal on dynamic plantar foot pressures in diabetic patients. Diab Med 9: 55-57

26. Edmonds ME, Blundell MP, Morris ME, Maelor Thomas E, Cotton LT, Watkins PJ (1986) Improved survival of the diabetic foot: the role of a specialist foot clinic. Quart J Med 232: 763-771

27. Macleod AF, Williams DRR, Sonksen PH, Boulton AJM (1991) Risk factors for foot ulcers in diabetic patients attending a hospital clinic. Diabetologia 34 [Suppl 2]: A39 (Abstract)

Received: 20 January 1992

and in revised form: 16 March 1992

Dr. A. J. M. Boulton

Department of Medicine

Manchester Royal Infirmary

Oxford Road

Manchester

M139WL

UK 